\title{
Avaliação do conhecimento sobre aleitamento materno de primíparas atendidas em uma maternidade de Teresina, Piauí
}

\author{
Evaluation of the knowledge about breastfeeding of primiparous women met in a maternity \\ hospital in Teresina, Piauí
}
Evaluación de los conocimientos sobre la lactancia materna de mujeres primíparas atendidas en una maternidad en Teresina, Piauí

\begin{abstract}
Barhbara Brenda Dias Garcez ${ }^{1 *}$, Allan Dellon da Silva ${ }^{1}$, Jailson Costa Lima ${ }^{1}$, Teresinha Soares Pereira Lopes², Luciana Tolstenko Nogueira ${ }^{1}$.
\end{abstract}

\section{RESUMO}

Objetivo: Investigar o conhecimento sobre o aleitamento materno de primíparas atendidas em uma maternidade de Teresina, PI. Métodos: Trata-se de um estudo quantitativo, descritivo e transversal; conduzido com 36 primíparas, com idade de 16 a 41 anos, utilizando amostra por conveniência. $O$ conhecimento das primíparas foi avaliado por aplicação de um questionário adaptado relativo ao período da amamentação exclusiva. Resultados: A média de idade das primíparas entrevistadas foi de 24,3 anos, a cesárea foi o tipo de parto mais prevalente entre as participantes (75\%). 66,67\% realizavam aleitamento materno exclusivo, 47,22\% relataram ter dificuldades no processo de amamentação e 52,78\% não receberam informações sobre aleitamento materno. A maioria das primíparas declarou possuir poucas dúvidas acerca do processo de aleitamento e amamentação, entretanto quando questionado sobre a pega e postura corretas e período de $\mathrm{AME}$, o número de primíparas que apresentavam dúvidas aumentou. Conclusão: Identificou-se que as primíparas têm um nível de conhecimento regular acerca do aleitamento materno, além disso, obtevese um elevado percentual de primíparas que relataram não ter recebido informações sobre aleitamento materno durante o período gravídico-puerperal.

Palavras-chave: Aleitamento materno, Período pós-parto, Conhecimento.

\begin{abstract}
Objective: To investigate the knowledge about breastfeeding of primiparous women met in a maternity hospital in Teresina, PI. Methods: This is a quantitative, descriptive and cross-sectional study, conducted with 36 primiparous women, aged 16 to 41 years, using a convenience sample. The knowledge of primiparous women was evaluated by applying an adapted questionnaire related to the period of exclusive breastfeeding. Results: The mean age of the primiparous women interviewed was 24.3 years, cesarean section was the most prevalent type of delivery among the participants (75\%), $66.67 \%$ were exclusively breastfeeding, $47.22 \%$ reported having difficulties in the breastfeeding process and $52.78 \%$ did not receive information about breastfeeding. Most primiparous women reported having little doubt about the breastfeeding and breastfeeding process, however, when asked about the correct latch and posture and period of EBF, the number of primiparous women who presented doubts increased. Conclusion: Primiparous women have a regular level of knowledge about breastfeeding, in addition to a high percentage of primiparous women who reported not having received information about breastfeeding during the pregnancy-puerperal period.
\end{abstract}

Keywords: Breastfeeding, Postpartum period, Knowledge.

1Universidade Estadual do Piauí (UESPI), Teresina - PI. *E-mail: barhbarabrenda@hotmail.com

2Universidade Federal do Piauí (UFPI), Teresina - PI.

SUBMETIDO EM: 7/2020

ACEITO EM: 8/2020

PUBLICADO EM: 11/2020 


\section{RESUMEN}

Objetivo: Investigar los conocimientos sobre la lactancia materna de mujeres primíparas atendidas en una maternidad en Teresina, PI. Métodos: Este es un estudio cuantitativo, descriptivo y transversal; con 36 primíparas, de 16 a 41 años de edad, utilizando una muestra de conveniencia. El conocimiento de las mujeres primíparas fue evaluado aplicando un cuestionario adaptado relacionado con el período de lactancia materna exclusiva. Resultados: La edad media de las mujeres primíparas entrevistadas fue 24,3 años, la cesárea fue el tipo de parto más frecuente entre las participantes (75\%), 66,67\% estaban amamantando exclusivamente, $47,22 \%$ reportaron tener dificultades en el proceso de lactancia materna y 52,78\% no recibieron información sobre la lactancia materna.La mayoría de las primíparas informaron tener pocas dudas sobre el proceso de lactancia materna, sin embargo, cuando se preguntó sobre el agarre y la postura correctos y el período de AME, el número de mujeres primíparas que presentaron dudas aumentó. Conclusión: Se identificó que las mujeres primíparas tienen un nivel regular de conocimiento sobre la lactancia materna, además, se obtuvo un alto porcentaje de mujeres primíparas que informaron no haber recibido información sobre la lactancia materna durante el período de embarazo-puerperio.

Palabras clave: Lactancia materna, Período posparto, Conocimiento.

\section{INTRODUÇÃO}

O aleitamento materno é um processo que envolve fatores fisiológicos, ambientais e emocionais que garantem a saúde da criança e resulta em notáveis benefícios tanto para o recém-nascido quanto para a mãe, além de proporcionar um impacto positivo no crescimento e desenvolvimento do bebê, garantindo vantagens imunológicas, psicológicas e nutricionais (COELHO AS, et al., 2019; LIMA VF, 2017).

Segundo o Ministério da Saúde (MS), o aleitamento materno exclusivo (AME) é a forma ideal e necessária para a alimentação da criança até o sexto mês de vida, depois desse período é que se inicia a introdução de alimentos de qualidade compatíveis com a idade do bebê, e enfatiza-se que se pode manter o leite materno até os 2 anos de idade ou mais de forma complementar para a alimentação do bebê (BRASIL, 2015).

Por essas razões, desde a primeira consulta pré-natal, as gestantes são incentivadas à amamentarem seus bebês. Assim, quando a hora do parto chegar elas estarão com uma bagagem adequada de conhecimentos sobre os benefícios do AME. Deste modo, a informação correta sobre o processo de amamentação favorece uma maior segurança para as mães amamentarem seus bebês logo após o parto (NASCIMENTO AMR, et al., 2019).

Acrescenta-se como relevante a maneira que os profissionais de saúde abordam as mulheres, pois às vezes as dúvidas e aflições das mães frente aos desafios a serem enfrentados no processo de aleitamento materno podem não ser colocadas de maneira espontânea pelas mesmas (ALMEIDA JM, et al., 2015).

Porém, para que isso possa ocorrer, é necessário que os profissionais responsáveis pela assistência médica estejam bem preparados, pois o êxito da amamentação dependerá muitas vezes das orientações oferecidas à nutriz. Desta forma, é imprescindível a efetivação de ações educativas diversas que promovam o AME com o objetivo de contribuir para a redução da morbimortalidade infantil e prevenir o desmame precoce (NASCIMENTO AMR, et al., 2019).

Ademais, os profissionais de saúde, como médicos, enfermeiros, nutricionistas, fisioterapeutas, dentistas, terapeutas ocupacionais, fonoaudiólogos, dentre outros, e mais especificamente os médicos, precisam compreender a amamentação como um processo importante dessa fase, porque as pacientes respeitam muito a figura do médico como detentor de conhecimento e depositam sua confiança nele. Por conta disso a amamentação deve ser muito valorizada e enfatizada nas consultas médicas (ALMEIDA JM, et al., 2015).

Mas, apesar da OMS ter recomendado o AME nos primeiros seis meses de vida do bebê, essa adesão é um desafio para os serviços de atenção à saúde da mulher e da criança (FERREIRA HLOC, et al., 2018). Porque mesmo com o apoio vindo da legislação brasileira, que considera a amamentação como um dos sete eixos estratégicos das ações e serviços de saúde da criança, o desmame precoce, que acontece antes do 
lactente ter completado seis meses, ainda é uma frequente e indesejável realidade (BRASIL, 2015b; ANDRADE HS, et al., 2018).

Devido, provavelmente, ao ato de amamentar ter que ser exercido por excelência e por vontade da mulher, que sofre influência do meio social, da rede de relações de suporte, influência de sua história de vida, das suas experiências familiares e de suas amigas, de fatores demográficos, culturais e sociais no seu desejo e vontade de amamentar seu bebê (PRIMO CC, et al., 2016).

Destaca-se, assim, o desmame precoce como um importante problema de saúde pública, relacionado a fatores como idade materna, primariedade, inserção da mulher no mercado de trabalho, baixo nível de escolaridade, uso precoce de fórmulas lácteas, chupetas e mamadeiras (ALMEIDA IS et al., 2010; BATISTA LL, et al., 2018).

Outras prováveis causas para o desmame precoce relacionam-se com fatores que dificultam a amamentação como: erro na posição de pega do bebê e ordenha, fissura mamilar, mamas ingurgitadas e dor na amamentação (DIAS BVB, et al., 2019).

Além disso, alguns mitos associados ao conhecimento ineficaz da mãe em relação ao processo de amamentação podem corroborar com o desmame precoce como o fato de muitas mulheres crerem que o seu leite possa ser fraco ou então realizar associação entre o tamanho da mama com a capacidade de produzir leite materno (AMARAL LJ, et al., 2015).

A amamentação ainda se configura como um ato permeado por mitos, crenças e valores transmitidos de geração em geração, sendo fortemente influenciada pela rede de apoio social da puérpera (PRATES LA, et al., 2015). Em decorrência disso, as puérperas necessitam de apoio, incentivo e orientação, uma vez que não basta apenas fornecer a informação sobre a importância do leite materno, pois a divulgação das informações acerca da temática devem se basear na efetivação do cuidar de modo empático, integral, sem preconceitos ou pressupostos que permitam adentrar no mundo da vida da primípara, tentando compreender as influências referentes ao processo de aleitamento materno individual de cada mãe (ALMEIDA IS, et al., 2010).

Nesse sentido, este estudo teve como objetivo principal investigar o conhecimento sobre o aleitamento materno de primíparas atendidas em uma maternidade de referência para alta complexidade da cidade de Teresina, PI.

\section{MÉTODOS}

Trata-se de um estudo de natureza descritiva, transversal e com enfoque quantitativo, realizado em uma Maternidade Pública do Estado do Piauí, que teve como amostra 36 mães primíparas atendidas nessa instituição (amostra por conveniência).

A pesquisa somente teve início após aprovação pelo Comitê de Ética em Pesquisa da Universidade Estadual do Piauí, via Plataforma Brasil, com data de aprovação em 15 de janeiro de 2018, parecer no 2.466.971, CAAE: 68226417.7.0000.5209, conforme a resolução 466/12 do Conselho Nacional de Saúde (BRASIL, 2012), mediante a assinatura de duas vias de um Termo de Consentimento Livre e Esclarecido (TCLE) pelo participante, ficando uma via com a mesma e outra com a pesquisadora responsável.

A coleta de dados ocorreu no período compreendido entre agosto de 2018 a agosto de 2019 durante um dia da semana. Para este fim, foi realizada a abordagem das pacientes na maternidade com aplicação dos questionários mediante anuência das participantes. O local de aplicação dos questionários foi a sala de odontologia do Instituto de Perinatologia da maternidade, os quais eram aplicados às quartas-feiras devido a disponibilidade da sala cedida pela profissional responsável.

Durante a abordagem das pacientes, foi realizado a exposição dos objetivos desta pesquisa e sanadas quaisquer dúvidas referentes as perguntas contidas no questionário. Posteriormente foi realizada a leitura e assinatura do TCLE, em seguida, foi acordada a coleta de dados, por meio da aplicação de um questionário com as primíparas em forma de entrevista, para este fim utilizou-se o questionário sobre amamentação e dor que foi adaptado do estudo de Carreira CM (2008). 
O questionário utilizado neste estudo possui como ênfase os seguintes fatores para avaliação e obtenção de dados para a pesquisa: a importância do aleitamento materno, a pega correta, as principais dificuldades enfrentadas por mães primíparas durante o período de amamentação e a importância nutricional do leite materno na prevenção de doenças. O questionário era composto por 5 sessões: caracterização da amostra; perguntas relativas à gravidez atual; perguntas relacionadas ao aleitamento materno; prática da amamentação e dificuldades durante a amamentação. Além disso, ao final do questionário foram esclarecidas as principais dúvidas quanto à amamentação que as primíparas possuíam.

Para responder à questão central da pesquisa foram avaliadas as respostas dadas pelas entrevistadas no instrumento de coleta de dados utilizado e dessa maneira foi possível analisar o nível de conhecimento de primíparas sobre aleitamento materno em uma maternidade de referência para alta complexidade do município de Teresina-PI.

Para avaliação estatística dos dados coletados foi realizado análise quantitativa dos dados de forma descritiva, o material do questionário foi organizado e tabulado no Software Microsoft Excel, no qual as variáveis foram apresentadas por meio de média e as categóricas por frequências e porcentagens.

\section{RESULTADOS}

Participaram do estudo 36 mães primíparas atendidas em uma maternidade pública de referência de Teresina, com média de idade de $24,30 \pm 6,26$ anos. Na amostra houve apenas primíparas com gestações a termo com registro de idade gestacional entre 34 e 41 semanas.

Das participantes entrevistadas, apenas $22,89 \%$ citaram possuir ensino superior completo ou incompleto. Quanto ao tipo de parto a qual foi submetida, a cesárea foi mais prevalente entre as entrevistadas (75\%), além disso, quando questionadas acerca do tipo de aleitamento materno realizado, $(66,67 \%)$ citaram o aleitamento materno exclusivo (Tabela 1).

Tabela 1 - Distribuição das gestantes entrevistadas, segundo a escolaridade, tipo de parto realizado, e tipo de aleitamento realizado.

\begin{tabular}{ccc}
\hline Variáveis & $\mathbf{n}$ & (\%) \\
\hline Escolaridade & 8 & $22,89 \%$ \\
\hline Ensino superior * $^{*}$ & 27 & \\
\hline Tipo de Parto realizado & & \\
\hline Cesária & 27 & $75 \%$ \\
Via vaginal & 7 & $19,44 \%$ \\
Não informado & 2 & $5,56 \%$ \\
\hline Tipo de aleitamento realizado & & \\
\hline Aleitamento materno exclusivo & 24 & $66,67 \%$ \\
Sem aleitamento materno exclusivo & 12 & $33,33 \%$ \\
\hline
\end{tabular}
Legenda: ${ }^{*}$ Completo ou Incompleto
Fonte: Garcez BBD, et al., 2020. Dados extraídos por meio da utilização
de questionário adaptado de Carreira CM (2008).

Em relação ao período de aleitamento materno exclusivo proposto pelo Ministério da Saúde somente metade $(50 \%)$ relataram saber dessa informação, e no que diz respeito aos conhecimentos recebidos durante todo o processo gravídico-puerperal, acima de 50\% das primíparas declararam não ter recebido informações sobre aleitamento durante a gravidez, e mais da metade (53,78\%) citou enfrentar dificuldade no processo de amamentação (Gráfico 1). 
Gráfico 1 - Distribuição de porcentagens quanto às informações sobre aleitamento materno e dificuldades no processo de amamentação.

$$
\text { - SIM } \square \text { NÃO }
$$

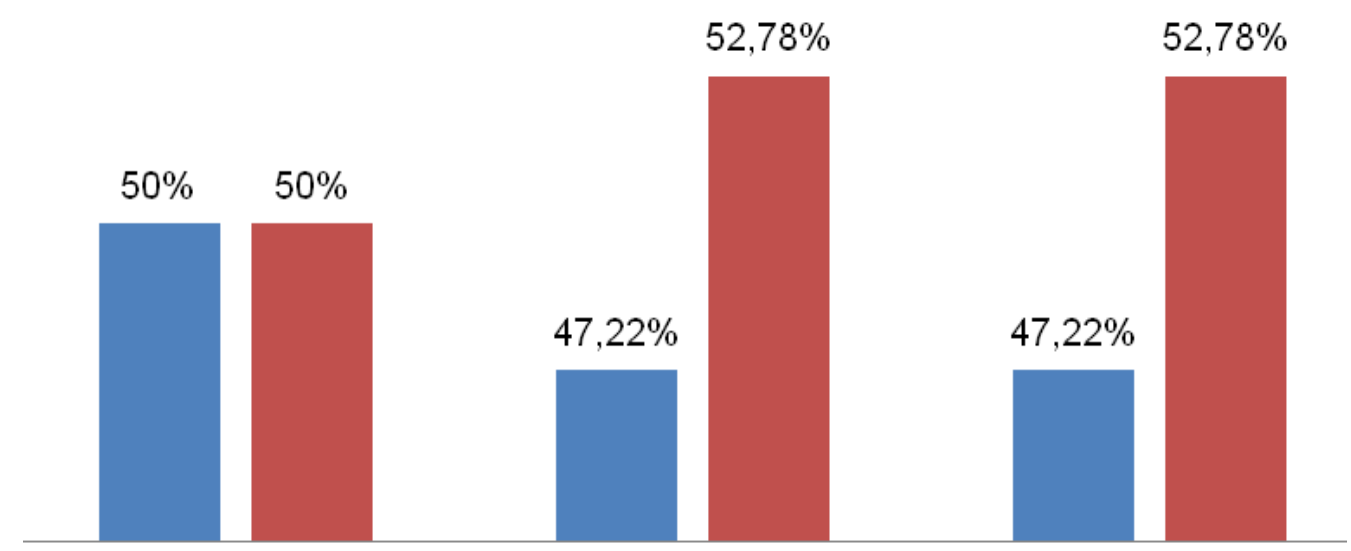

Conhecimento do período Recebeu informação sobre Enfrentou dificuldade na recomendado de aleitamento materno aleitamento amamentação exclusivo

Fonte: Garcez BBD, et al., 2020. Dados extraídos por meio da utilização de questionário adaptado de Carreira CM (2008).

Quando questionadas acerca da presença de risco na gravidez e o motivo a ser considerada de risco a maioria das primíparas entrevistadas relatou ter tido gravidez de risco $(63,89 \%)$, sendo a patologia mais citada a pré-eclâmpsia $(36,11 \%)$ (Tabela 2 ).

Tabela 2 - Distribuição das frequências e porcentagens em função do risco na gravidez.

\begin{tabular}{ccc}
\hline Variáveis & $\mathbf{n}$ & $\mathbf{( \% )}$ \\
\hline Gravidez de risco & & \\
\hline Sim & 23 & $63,89 \%$ \\
Não & 13 & $36,11 \%$ \\
\hline Motivo do risco em caso positivo & & \\
\hline Pré-eclâmpsia & 13 & $36,11 \%$ \\
Diabetes Gestacional & 2 & $2,77 \%$ \\
Ameaça de parto prematuro & 2 & $2,77 \%$ \\
Amniorrexe & 3 & $8,33 \%$ \\
Outros & 4 & $11,11 \%$
\end{tabular}

Fonte: Garcez BBD, et al., 2020. Dados extraídos por meio da utilização de questionário adaptado de Carreira CM (2008).

No que diz respeito às principais dificuldades enfrentadas no processo de aleitamento materno, metade das entrevistadas (50\%) citaram a presença de dor, e somente 38,89\% apontaram o ingurgitamento mamário como uma das principais dificuldades (Gráfico 2). 
Gráfico 2 - Distribuição de porcentagens quanto às principais dificuldades enfrentadas no aleitamento materno.

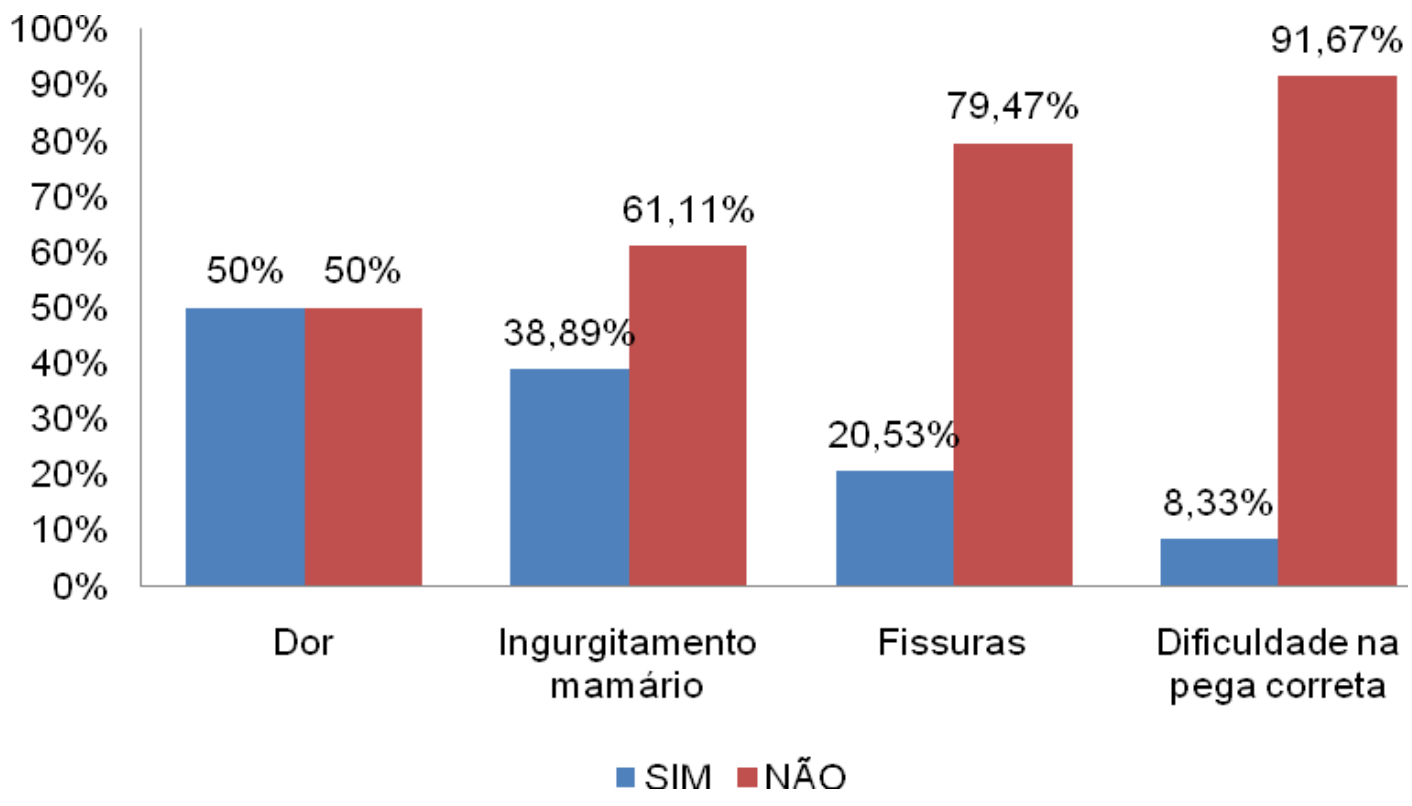

Fonte: Garcez BBD, et al., 2020. Dados extraídos por meio da utilização de questionário adaptado de Carreira CM (2008).

Quando questionadas acerca de dúvidas em relação ao aleitamento materno a maioria das primíparas declarou possuir poucas dúvidas acerca do processo de aleitamento e amamentação, entretanto quando foi questionado sobre a pega e postura corretas esse número aumentou (Gráfico 3).

Gráfico 3 - Distribuição de frequências em função da presença de dúvidas em relação ao aleitamento materno.

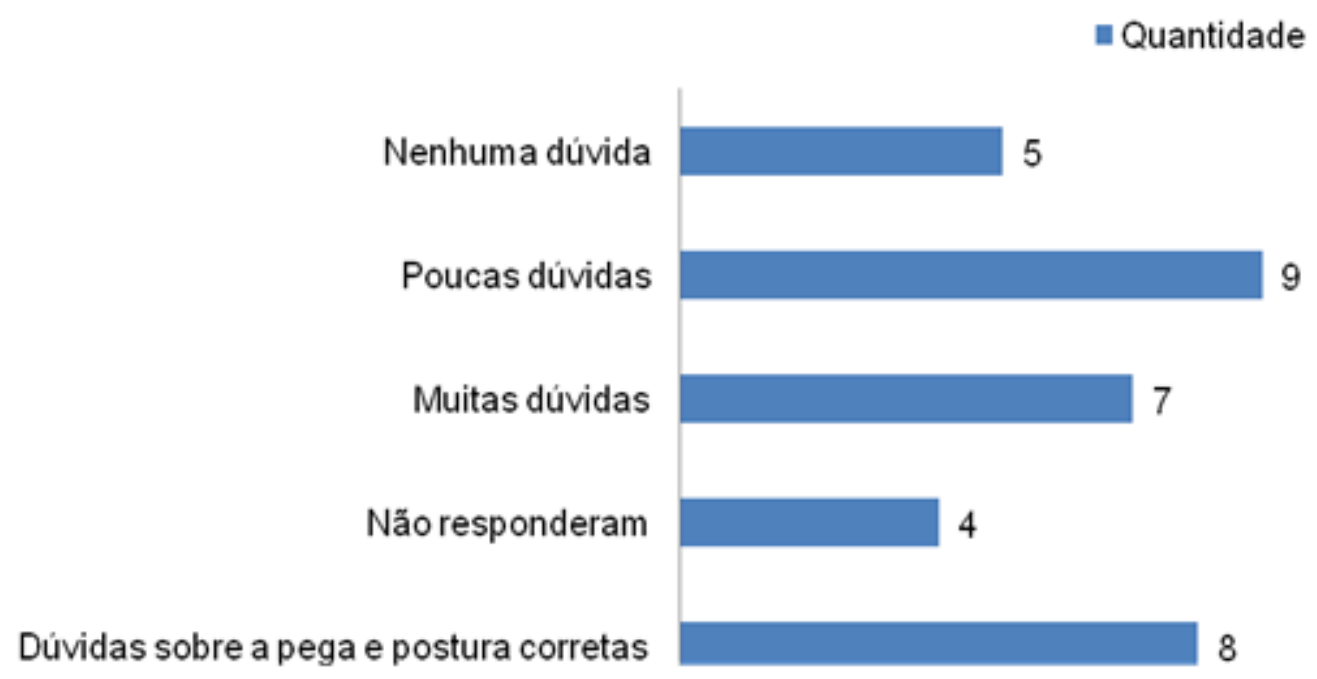

Fonte: Garcez BBD, et al., 2020. Dados extraídos por meio da utilização de questionário adaptado de Carreira CM (2008).

Em relação as primíparas que receberam informações sobre aleitamento materno durante o período gravídico-puerperal o profissional mais citado pelas pacientes no fornecimento dessas informações foi o enfermeiro (a) (Gráfico 4). 
Gráfico 4 - Distribuição de frequências em função de qual profissional passou informações acerca do aleitamento materno.

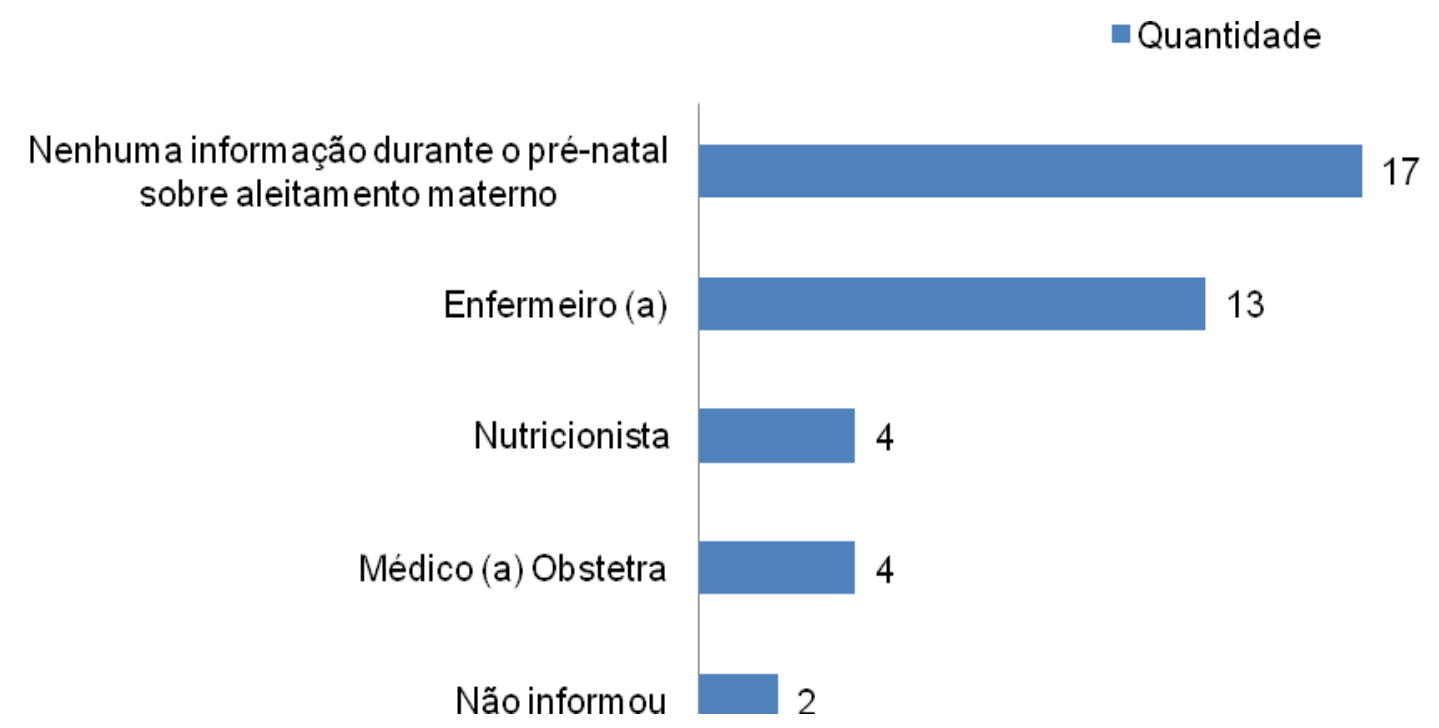

Fonte: Garcez BBD, et al., 2020. Dados extraídos por meio da utilização de questionário adaptado de Carreira CM (2008).

\section{DISCUSSÃO}

Informações específicas sobre amamentação nos períodos de pré-natal e pós-parto são imprescindíveis para a garantia da melhor assistência e prevenção do desmame precoce, colaborando para o sucesso do processo de amamentação (SOUZA SF, et al., 2017). Visto que, estudos evidenciam que ainda é muito frequente as puérperas, sobretudo as primíparas, apresentarem dificuldade para a continuidade do AME durante o período recomendado, bem como desconhecerem os benefícios do aleitamento materno (ANDRADE HS, et al.,2018; SILVA AM, et al., 2018).

As variáveis sociodemográficas analisadas para correlacionar ao nível de conhecimento foram a idade, escolaridade e tipo de parto realizado. E com base nos dados encontrados nesse estudo tem-se que a maioria das primíparas não possui ensino superior $(77,15 \%)$, esse resultado é semelhante ao achado de um estudo realizado por Santos GMR, et al. (2015), onde $72 \%$ das entrevistadas não possuíam curso superior. Esse é um dado importante uma vez que o grau de instrução pode influenciar na assimilação e interpretação das informações (SOUZA SF, et al., 2017).

No que diz respeito ao tipo de parto, tem-se que $75 \%$ das primíparas entrevistadas foram submetidas ao parto cesárea. Esse valor elevado de cesárias, possivelmente, pode ser justificado quando verificamos algumas características do local do estudo, pois as primíparas foram atendidas na maternidade de referência para casos de alta complexidade do estado do Piauí, ademais a maternidade além de atender a demanda de casos do município de Teresina-PI, ainda recebe casos de municípios de outros estados.

Porém esse alto valor proporcional no número de realização desse tipo de parto entre as primíparas entrevistadas deve ser analisado com cautela, pois a OMS recomenta que a taxa ideal de cesárea fique em torno de 10 a 15\%, pois por se tratar de intervenção cirúrgica somente pode ser prescrita em situações nas quais o parto normal não seja mais o recomendado (BRASIL, 2019).

Quanto ao tipo de aleitamento realizado, obteve-se que $66,67 \%$ das participantes realizavam AME, esse percentual encontrado é significativamente superior ao que foi registrado no estudo de Santos GMR, et al. (2015), que foi de $40 \%$. Por outro lado, de acordo com dados de um estudo realizado na Polônia, um alto percentual (43\%) da amostra não realizou a amamentação exclusiva, e identificou ainda que quanto maior o nível de conhecimento materno sobre amamentação, menores as chances de desistência da AME antes do período recomendado (ZIELINSKA MA, et al., 2017). 
Um alto percentual $(63,88 \%)$ das primíparas entrevistadas relataram ter tido gravidez de risco, sendo a patologia mais citada a pré-eclâmpsia $(36,11 \%)$, seguida por amniorrexe $(8,33 \%)$, dessa forma com base nesses dados pode-se compreender o motivo do número alto de cesáreas realizadas. Resultado semelhante foi encontrado no estudo de Moraes PGS, et al. (2014) realizado em uma maternidade no município do Recife, onde a cesariana foi a via de parto realizada em $65,80 \%$ das participantes, e a pré-eclâmpsia está entre as complicações obstétricas mais citadas correspondendo a 45,30\% da amostra estudada.

Outro achado relevante foi o fato de $47,22 \%$ das primíparas entrevistadas afirmarem não terem recebido informações acerca de como realizar a amamentação, esse resultado corrobora com os dados encontrados por Carvalho JLS, et al. (2016), que constatou que 57,5\% das entrevistadas responderam de maneira errada quando foram indagadas sobre a posição adequada para amamentar.

Entretanto, diferente dos resultados encontrados, um estudo realizado por Azevedo DS, et al. (2010), obteve que $86,9 \%$ da primíparas entrevistadas relataram ter recebido orientações acerca do aleitamento materno, no entanto $9,1 \%$ dessas pacientes relataram receber orientações somente no pré-natal e $40,1 \%$ somente na maternidade, esse baixo percentual de pacientes orientadas durante o período de pré-natal contribui para a insegurança dessas pacientes durante o período puerperal.

Assim, verifica-se que apesar da AME ser muito importante e trazer muitos benefícios tanto para mãe quanto para o seu bebê, as informações que são repassadas para as mães ainda não obtiveram uma assimilação adequada por parte das primíparas, possivelmente pela falta de acompanhamento e orientações no momento adequado.

Um dos fatores que também deve ser observado durante esse período é em relação às principais dificuldades enfrentadas no processo de aleitamento materno, e quando questionadas acerca das dificuldades enfrentadas, as mais citadas foram a presença de dor $(50 \%)$, sofreram com ingurgitamento mamário (38,89\%), apresentaram fissuras $(20,53 \%)$ e relataram dificuldade na pega correta $(8,33 \%)$. Problemas semelhantes aos citados no estudo também foram encontrados no estudo de Silva AM, et al. (2018), como fissuras da mama e a mastite puerperal.

Além disso, apesar de não ter encontrado resultados semelhantes no que diz respeito às intercorrências que dificultam a amamentação, até porque a pesquisa não se limitou à primíparas, o estudo de Carreiro JA, et al. (2018) aponta para a dificuldade em relação ao posicionamento incorreto da mãe e da criança durante a amamentação, além da preensão e sucção de forma incorreta, o que também podem influenciar para o desmame precoce.

Outra evidência encontrada no estudo em tela foi que $50 \%$ das entrevistadas citaram ter conhecimento acerca do período recomendado de AME, um resultado baixo apesar da ampla divulgação dessa informação, pois vários órgãos internacionais e nacionais preconizam que a amamentação deve ser fonte de alimentação exclusiva para bebês até 6 meses de idade. Esse percentual é semelhante ao encontrado em um estudo realizado com puérperas primíparas no município de Cáceres (MT), onde $50 \%$ da amostra estudada citaram ter conhecimento do que se trata o aleitamento materno exclusivo, bem como do período recomendado pelo Ministério da Saúde (ASSIS ELA, et al., 2014).

Em seguida, constatou-se que a maioria das primíparas declarou possuir poucas dúvidas acerca do processo de aleitamento e amamentação, entretanto quando questionado sobre a pega e postura corretas, período de $\mathrm{AME}$, vantagens da amamentação para a mãe e para a criança esse número de primíparas que apresentavam dúvidas aumentou. Essa contraposição também é observada em um estudo realizado na Nigéria, onde as pacientes entrevistadas relataram ter consciência da AME e foram capazes de definir corretamente, no entanto quando questionadas acerca de outras informações, por exemplo, os benefícios da amamentação para a mãe e o bebê, houve discrepância nas respostas.

Com isso, obteve-se que mais da metade $(58,7 \%)$ da amostra estudada demonstraram conhecimento inadequado sobre AME, e acrescentaram ainda que somente $62,7 \%$ das primíparas pretendiam amamentar exclusivamente (IHUDIEBUBE-SPLENDOR CN, et al., 2019). Por outro lado, conforme dados do estudo de Carvalho JLS, et al. (2016), realizado com puérperas, 57,5\% da amostra estudada não possuía conhecimento 
acerca da posição adequada para amamentar e promover uma amamentação eficiente, porém demonstraram conhecimento quando questionadas sobre as vantagens da amamentação exclusiva, apresentando um percentual de $81,8 \%$ nesse quesito.

Ademais, de acordo com dados de um estudo realizado na cidade de Porto Alegre (RS), no período puerperal as dúvidas mais comuns relacionadas ao processo de amamentação estão justamente relacionadas à pega correta do recém-nascido e presença de dor nas mamas, além disso, esse estudo enfatiza ainda que as primíparas apresentaram mais dúvidas e/ou questionamentos quando comparado à puérperas que já possuíam filhos (CASTELLI CTR, et al., 2014).

No que diz respeito ao acesso a informações sobre aleitamento materno durante o período gravídicopuerperal, o profissional mais citado como fonte dessas informações foi o enfermeiro, seguido do médico e do nutricionista. Esses resultados também foram encontrados no estudo de Azevedo DS, et al. (2010), onde os enfermeiros também foram os mais citados, correspondendo a $34,9 \%$, seguido dos médicos $(19,4 \%)$, possivelmente pelo fato desses serem alguns dos profissionais de maior contato com essas pacientes durante o período de pré-natal e puerpério.

Acrescenta-se que o presente estudo apresentou limitações devido ao baixo número da amostra, isso se deve em parte ao tipo de estudo escolhido, que envolveu amostra por conveniência, por ser um estudo transversal ocorrido em período de tempo determinado para a aplicação dos questionários, por outro lado outra limitação se impõe e relaciona-se com a dificuldade na obtenção de um maior número de amostra devido ao critério de inclusão do estudo ser mãe primípara, pois a maior parte das mulheres abordadas no momento da entrevista não se enquadrava nesse critério, além disso, algumas gestantes relataram pressa em resolver suas atividades diárias e responder aos questionários representaria mais um momento de permanecer na maternidade, o que lhes custaria seu tempo.

\section{CONCLUSÃO}

A presente pesquisa evidenciou que as primíparas têm um nível de conhecimento regular acerca do aleitamento materno, além disso, obteve-se um elevado percentual de primíparas que relataram não ter recebido informações sobre aleitamento materno durante o período gravídico-puerperal. Esse conhecimento deve ser facilitado às pacientes ainda no período pré-natal, pois fica evidente a existência de uma fragmentação na assistência prestada e que a mesma precisa ser mais bem aperfeiçoada. Salienta-se, que profissionais e instituições públicas necessitam intervir positivamente com o objetivo de facilitar o acesso a melhores informações sobre AME, bem como políticas públicas devem ser mais estimuladas e fomentadas para garantir uma melhor assistência e apoio na prevenção do desmame precoce.

\section{AGRADECIMENTOS E FINANCIAMENTO}

Agradecemos primeiramente à nossa instituição de ensino superior, Universidade Estadual do Piauí UESPI, juntamente com o Governo do Estado do Piauí pela oportunidade que nos foi concedida e pelo apoio institucional do Programa Institucional de Bolsas de Iniciação Científica (PIBIC), vinculado a PROP/UESPI. Agradecemos ainda aos professores e alunos da Universidade Federal do Piauí vinculados ao Programa Preventivo de Gestantes e Bebês que cedeu seu espaço físico para a realização do estudo e ao Instituto de Perinatologia Social do Piauí.

\section{REFERÊNCIAS}

1. ALMEIDA IS, et al. Amamentação para mães primíparas: perspectivas e intencionalidades do enfermeiro ao orientar. Cogitare Enfermagem, 2010; 15(1):19-25.

2. ALMEIDA JM, et al. Apoio ao aleitamento materno pelos profissionais de saúde: revisão integrativa da literature. Revista Paulista de Pediatria, 2015; 33(3): 355-362.

3. AMARAL LJ, et al. Fatores que influenciam na interrupção do aleitamento materno exclusivo em nutrizes. Revista Gaúcha de Enfermagem, 2015; 36(esp):127-134.

4. ANDRADE HS, et al. Fatores relacionados ao desmame precoce do aleitamento materno. Revista Brasileira de Medicina de Família e Comunidade, 2018; 13(40):1-11. 
5. ASSIS ELA, et al. Dificuldades enfrentadas por puérperas primíparas em relação ao aleitamento materno exclusivo. Gestão e Saúde, 2014; 5(3): 808-819.

6. AZEVEDO DS, et al. Conhecimento de primíparas sobre os benefícios do aleitamento materno. Revista da Rede de Enfermagem do Nordeste, 2010; 11(2): 53-62.

7. BATISTA LL, et al. Association between pacifier use and bottle feeding and unfavorable behaviors during breastfeeding. Jornal de Pediatria, 2018; 94(6): 596-601.

8. BRASIL. Conselho Nacional de Saúde. Resolução no 466 de 12 de dezembro de 2012. Diretrizes e normas regulamentadoras de pesquisa envolvendo seres humanos. Brasília, 2012.

9. BRASIL. Ministério da Saúde. Política Nacional de Atenção Integral à Saúde da Criança (PNAISC) no âmbito do Sistema Único de Saúde (SUS). Portaria no 1.130, de 5 de agosto de 2015 . Disponível em: https://bvsms.saude.gov.br/bvs/saudelegis/gm/2015/prt1130_05_08_2015.html. Acesso em: 5 jul. 2020.

10. BRASIL. Ministério da Saúde. Cadernos de Atenção Básica. Saúde da criança aleitamento materno e alimentação complementar, 2015. Disponível em: https://bvsms.saude.gov.br/bvs/publicacoes/saude_crianca_aleitamento_materno_cab23.pdf. Acessoem: 5 jul. 2020.

11. BRASIL. Conselho Nacional de Saúde. Recomendação no 038 de 23 de Agosto de 2019. Disponível em: https://conselho.saude.gov.br/images/Reco038.pdf . Acesso em: 7 jul. 2020.

12. CARREIRA LM. Amamentação e dor. Dissertação (Mestrado em Medicina) - Faculdade de Ciências da Saúde. Universidade da Beira Interior.Covilhã, Portugal, 2008; Anexo: Questionário sobre Aleitamento Materno: 1- 4.

13. CARREIRO JA, et al. Dificuldades relacionadas ao aleitamento materno: análise de um serviço especializado em amamentação. Acta Paulista de Enfermagem, 2018; 31(4):430-438.

14. CARVALHO JLS, et al. Conhecimento das mães sobre aleitamento materno exclusivo e alimentação complementar. Saúde em Redes, 2016; 2(4): 383-392.

15. CASTELLI CTR, et al. Identificação das dúvidas e dificuldades de gestantes e puérperas em relação ao aleitamento materno. Rev CEFAC, 2014; 16(4): 1178-1196.

16. COELHO AS, et al. A importância da amamentação na formação de vínculos afetivos saudáveis entre mamãe/bebê. BIUS, 2019; 12(5): 1-15.

17. DIASBVB, et al. Banco de leite humano de Jundiaí/SP: dificuldades percebidas durante a amamentação. Revista Científica de Enfermagem, 2019; 9(28): 83-91.

18. FERREIRA HLOC, et al. Fatores Associados à Adesão ao Aleitamento Materno Exclusivo. Revista Ciência \& Saúde Coletiva, 2018; 23(3): 683-690.

19. IHUDIEBUBE-SPLENDOR CN, et al. Exclusive Breastfeeding Knowledge, Intention to Practice and Predictors among Primiparous Women in Enugu South-East, Nigeria. J Pregnancy, 2019; 3:1-8.

20. LIMA VF. A importância do aleitamento materno: uma revisão de literatura. Trabalho de Conclusão de Curso (Graduação em Nutrição) - Departamento de Nutrição. Universidade Federal da Paraíba, João Pessoa, 2017 ; 38 p.

21. MORAES PGS, HOLANDA VR, PINHEIRO HDM. Perfil epidemiológico de primíparas atendidas em uma maternidade de alto risco [Epidemiological profile ofprimiparousattended in a high-riskmaternity]. Enfermagem Obstétrica, 2014; $1(2), 45-50$

22. NASCIMENTO AMR, et al. Atuação do enfermeiro da estratégia saúde da família no incentivo ao aleitamento materno durante o período pré-natal. Revista Eletrônica Acervo Saúde, 2019; 21: 1-8

23. PRATES LA, et al. Rede de apoio social de puérperas na prática da amamentação. Escola Anna Nery, 2015; 19(2): 310-315.

24. PRIMO CC, et al. Quais os fatores que influenciam as mulheres na decisão de amamentar? Investigación y EducaciónenEnfermeria, 2016; 34(1): 198-210.

25. SANTOS GMR, et al. Mitos e crenças sobre aleitamento materno que levam ao desmame precoce nas estratégias saúde da família no município de Firminópolis-GO. Revista Faculdade Montes Belos, 2015; 8(4): $177-202$.

26. SILVA AM, et al. Aleitamento materno exclusivo: empecilhos apresentados por primíparas. Revista de Enfermagem UFPE online, 2018; 12(12): 3205-3211.

27. SOUZA SF, et al. Perfil demográfico e levantamento dos conhecimentos sobre aleitamento materno de puérperas atendidas em uma maternidade pública da região metropolitana de Belo Horizonte: resultado de um projeto de extensão. Conecte-se! Revista Interdisciplinar de Extensão, 2017; 1(1): 124-134.

28. ZIELINSKA MA, et al. Breastfeeding knowledge and exclusive breastfeeding of infants in first six months of life. RocznikiPaństwowegoZakładuHigieny, 2017; 68(1). 